\title{
1 Light and noise pollution impacts specialist wildlife species disproportionately
}

2 Short title: Wildlife vulnerability to sensory pollution

3 Mark A. Ditmer ${ }^{* 1}$, Clinton D. Francis ${ }^{2}$, Jesse R. Barber ${ }^{3}$, David C. Stoner ${ }^{4}$, Brett M.

4 Seymoure $^{5}$, Kurt M. Fristrup ${ }^{6}$, Neil H. Carter ${ }^{1}$

$6 \quad{ }^{1}$ School for Environment and Sustainability, University of Michigan, Ann Arbor, MI, USA

$7 \quad{ }^{2}$ Department of Biological Science, California Polytechnic University, San Luis Obispo,

8 CA, USA

$9 \quad{ }^{3}$ Department of Biological Sciences, Boise State University, Boise, ID, USA

10 4Department of Wildland Resources, Utah State University, Logan, UT, USA

11 5epartment of Fish, Wildlife, and Conservation Biology, Colorado State University, Fort

12 Collins, CO, USA

$13{ }^{6}$ National Park Service, Natural Sounds and Night Skies Division, Fort Collins, CO, USA

$15 \quad{ }^{*}$ Corresponding author: mark.ditmer@gmail.com 


\section{Abstract}

2 Global expansion of lighting and noise pollution alters how animals receive and interpret

3 environmental cues. Yet we lack a cross-taxon understanding of how animal traits

4 influence species vulnerability to this growing phenomenon. This knowledge is needed

5 to improve the design and implementation of policies that mitigate or reduce sensory

6 pollutants. We present results from an expert knowledge survey that quantified the

7 relative influence of several ecological, anatomical, and physiological traits on the

8 vulnerability of terrestrial vertebrates to elevated levels of anthropogenic lighting and

9 noise. Our findings, based on 280 responses, highlight the increasing recognition

10 among experts that sensory pollutants are important to consider in management and

11 conservation decisions. Participant responses show mounting threats to species with

12 narrow niches; especially habitat specialists, nocturnal species, and those with the

13 greatest ability to differentiate environmental visual and auditory cues. Our results call

14 attention to the threat specialist species face and provide a generalizable understanding

15 of which species require additional considerations when developing conservation

16 policies and mitigation strategies in a world altered by expanding sensory pollutant

17 footprints. We provide a step-by-step example for translating these results to on-the-

18 ground conservation planning using two species as case studies.

19 Keywords: artificial nightlight, conservation planning, expert knowledge, expert survey,

20 light pollution, noise pollution, sensory ecology, sensory pollution 


\section{Introduction}

All organismal interactions with their environments are mediated by sensory

3 inputs. Global growth in two sensory pollutants, anthropogenic lighting and noise

4 (henceforth, "lighting" and "noise"), are fundamentally altering visual and auditory

5 performance for many species (Dominoni et al. 2020). Light pollution and noise are

6 pervasive, growing, and intensifying (Buxton et al. 2017; Kyba et al. 2017); altering

7 sensory environments at a global scale. Importantly, all organismal interactions with

8 their environments are mediated by sensory inputs, and these sensory pollutants both

9 disrupt environmental cues and ecological processes near their source and extend far

10 beyond the altered landcover (Barber, Crooks \& Fristrup 2010; Kyba et al. 2015b).

11 Approximately $80 \%$ of the IUCN's Global Key Biodiversity Areas experience excess

12 nightlight luminance (Garrett, Donald, \& Gaston 2019) and 12\% of the IUCN's

13 designated wilderness areas in North America experience anthropogenic noise above

14 natural levels (Buxton et al. 2017).

Numerous studies assessing the impacts of lighting or noise provide examples of

16 altered behaviors, and fitness costs have been documented (Longcore \& Rich 2004;

17 Francis \& Barber 2013; Gaston et al. 2013). Evaluating these examples from an

18 evolutionary perspective can reveal selective forces arising from novel stimuli (Swaddle

19 et al. 2015; Hopkins et al. 2018) and identify the plausible taxonomic and ecological

20 extents of similar effects. Noise reduces the ability to perceive acoustic signals while

21 lighting affects visual perception. Both can fundamentally alter spatial orientation and

22 create mismatched biological timings (Gaston et al. 2017). These sensory disturbances

23 in turn create a myriad of behavioral alterations, affecting orientation and movement 
1 (Slabbekoorn \& Bouton 2008; Cabrera-Cruz, Smolinsky, \& Buler 2018), communication

2 (Francis \& Barber 2013), foraging and hunting efficiency (Bennie et al. 2015; Bunkley \&

3 Barber 2015; Mason, McClure, \& Barber 2016), altered energy budgets (Read et al.

4 2014; Touzot et al. 2019) and predation risk (Francis \& Barber 2013; Ditmer et al.

5 2020a), along with increased physiological stress (Rolland et al. 2012; Ouyang, Davies,

6 \& Dominoni 2018).

Most impacts of these sensory pollutants have been demonstrated with a

8 relatively small number of species at local scales, primarily within North America and

9 Europe. Studies involving terrestrial mammals are especially scarce (Shannon et al.

10 2016). Nonetheless, recent research has also shown that variation in these sensory

11 pollutants better explains patterns of habitat selection than common ecological

12 variables, such as landcover (Kleist et al. 2017), and better reflects the dynamic human

13 footprint relative to other measurements (e.g., housing density; Ditmer et al. 2020b).

14 Biological and ecological traits have frequently been linked with species' vulnerability to

15 environmental change and threat of extinction (Chown 2012; Foden et al. 2013), but

16 with limited treatment in the context of vulnerabilities to lighting and noise (primarily

17 avian species; see Francis 2015; Senzaki et al. 2020). Therefore, for species where

18 scientific studies on the impacts of sensory pollutants are scarce or nonexistent,

19 assessing relationships among relevant traits and taxa is most practical for forecasting

20 species' responses, and developing policies and conservation actions.

Here, synthesizing knowledge from experts around the world, we ranked the

22 degree to which a range of ecological, anatomical, and physiological traits contribute to

23 a species' vulnerability to lighting and noise. Vulnerability is considered a function of 
1 exposure to a threat, sensitivity to the threat, and the corresponding adaptive capacity

2 (McCarthy et al. 2001). Given the lack of published data on the subject across different

3 taxa, we used an expert knowledge elicitation. This method has successfully been used

4 to develop conservation policy (Martin et al. 2012), especially for subjects with

5 incomplete scientific understanding (Foden et al. 2013), emerging threats (Klein et al.

6 2017), or resource limitations that preclude in depth studies (Carwardine et al. 2012;

7 Gerber et al. 2018). Our survey did not ask questions regarding exposure to sensory

8 pollutants, because levels may vary greatly within and among species and regions.

9 Instead we followed the approach by Foden et al. (2013), who incorporated data from

10 expert surveys to quantify the degree to which biological traits - reflecting sensitivity

11 (i.e., the degree to which the survival, persistence, fitness, performance, or regeneration

12 of a species is reliant on current night light and noise levels or characteristics) and

13 adaptive capacity (i.e., the capacity of the species to persist in situ, shift to suitable

14 microhabitats, or migrate to suitable regions [Dawson et al. 2011]) - influenced the

15 threats of climate change. We collected independent responses from numerous experts,

16 defined as sensory ecologists or individuals with $\sim 3$ or more years of study/experience

17 with a vertebrate species/genera/taxa, that have diverse experiences with a variety of

18 species across geographic and ecological regions. By leveraging the experience and

19 ecological knowledge of these experts, our aim was to identify the traits that influence

20 vulnerability to lighting and noise the most, such that any species can be preliminarily

21 assessed for their likelihood to respond to these sensory pollutants as has been done

22 for species vulnerability to climate change (Dawson et al. 2011).

\section{Materials and Methods}




\section{Survey development and design}

Using the methods of Foden et al. (2013), we designed an online survey (hosted

3 at Qualtrics.com) to assess how and to what degree select biological traits contribute to

4 anthropogenic light and noise vulnerability. We informed participants that the survey

5 was only considering direct, negative impacts of lighting and noise on adult, terrestrial

6 vertebrates. Traits incorporated into our survey were selected from recommendations

7 developed at a 3-day workshop of experts in sensory ecology and animal physiology,

8 where the effects of sensory pollutants and the mechanisms of disturbance were

9 extensively discussed across a diverse range of taxa (Dominoni et al. 2020). We

10 selected traits that were associated with increased extinction risk and allowed

11 participants to complete the survey regardless of their primary species or taxa studied.

12 As such, respondents were instructed not to consider idiosyncratic responses, but to

13 focus on traits that are generally linked to increased vulnerability across vertebrate taxa.

14 We provided definitions (and some examples) of each trait considered in the survey

15 (Table 1), and we based our definition of vulnerability (provided to respondents) on the

162001 Assessment Report, in which vulnerability is a function of exposure, sensitivity,

17 and adaptive capacity (McCarthy et al. 2001). We classified traits as either related to

18 ecological, anatomical/physiological sensitivity, or adaptive capacity (Table 1).

19 However, "use of migration" was the only trait classified as adaptive capacity, so we

20 grouped it with the ecological sensitivity traits in the Results.

The survey began with two questions on the importance of anthropogenic light

22 and noise within the systems the experts study and/or manage. The five response

23 options to these questions ranged from "very important", "important", "moderately 
1 important", "slightly important", and "not important". The next section elicited responses

2 on specific traits and how each is related to vulnerability from lighting and noise. We

3 asked experts about the impacts of lighting and noise (separately) on the same eight

4 ecological sensitivity traits and "use of migration". Because physiological and

5 anatomical sensitivity traits were specific to either vision or hearing, we asked experts

6 about the influence of lighting on six traits that were different from the seven traits

7 considering the impacts of noise (Table 1 ).

8 We asked experts to provide a numeric value in response to three questions for

9 each combination of sensory pollutant and trait. The first question asked about the

10 importance of the trait and its effect on vulnerability if levels of lighting or noise are

11 elevated. The six possible responses were: "0 - no effect”, "1 - small”, "2”, “3 -

12 medium","4", and "5 - large". The second question asked which direction of the trait's

13 magnitude ("0 = no effect”, "1 - lowest/smallest/least”, up to "5 -

14 highest/greatest/most"), or for some traits, specific categories (e.g., "nocturnal",

15 "diurnal", or "no effect") would increase vulnerability to lighting and noise the most

16 (Table 1, Figs. 1-4). We then asked experts to assess the level of certainty in their

17 responses (“0 - none” up to "5 - high”; see Figs. 1-4 for details).

\section{Survey data analysis}

We calculated the weighted mean and weighted standard deviation of the

20 responses indicating the level of influence on vulnerability to elevated levels of lighting

21 or noise for each trait using the expert's reported level of certainty to weight each

22 metric. We used the package 'diagis' (Helske 2018) in program R (R Core Team 2019)

23 to compute the estimates. The functions "weighted_mean" and "weighted_se" use 
1 probability weights instead of frequency weights. We constructed $95 \%$ confidence

2 intervals by multiplying the weighted standard error by 1.96 . The percentage of choices

3 among options describing the direction of the trait's magnitude were also calculated for

4 each trait and sensory pollutant type.

\section{Survey Elicitation}

We sought participants for our online survey from a variety of groups and

7 organizations that regularly had contact with species' experts. We first requested

8 participation on popular email listservs, such as ECOLOG-L, and through snowball

9 sampling in which survey participants recommend the survey to colleagues. We also

10 searched Google Scholar for authors who were experts in wildlife and sensory ecology,

11 producing a list of 135 and 34 potential participants, respectively. We sent emails to

12 those authors requesting their participation in the survey.

When reaching out we stated that we were interested in participants that include,

14 "sensory ecologists or those with $\sim 3$ or more years of study/experience with a particular

15 vertebrate species/genus/taxon. A PhD candidate studying sea turtle nesting success, a

16 biologist working in Everglades National Park for ten years, or an assistant professor

17 would all potentially be suitable for this survey." Respondents reported diverse areas of

18 expertise, including "astrophysicist with experience in animal behavior", and experience

19 working with a variety of species (primary area of expertise: mammal(s) $=43 \%$; bird(s) $=$

$2025 \%$; amphibian(s) = 13\%; invertebrate(s) = 8\%; reptile(s) = 5\%; fish = 5\%).

21 Our survey provided an informed consent document to all participants that

22 reminded the reader that participation was voluntary, it included detailed information on 
1 the purpose of the study, names and contacts of the principal investigators, and project

2 sponsors. Participants were informed that we would make every effort to protect

3 participants' confidentiality and we asked participants to sign and date the informed

4 consent form. The research protocols were approved by Boise State's University Office

5 of Research Compliance (approved IRB\#: 193-SB18-068). 
bioRxiv preprint doi: https://doi.org/10.1101/2021.02.18.431905; this version posted February 19, 2021. The copyright holder for this preprint (which was not certified by peer review) is the author/funder, who has granted bioRxiv a license to display the preprint in perpetuity. It is made available under aCC-BY-NC-ND 4.0 International license.

$1 \quad$ Table 1.) Summary of expert survey. Attributes include all biological traits that were assessed for their ability to increase vulnerability to anthropogenic night light and noise, the specific sensory pollutant we asked the expert to consider (light, noise or both) and the trait definition provided to expert within the survey. Experts were asked to assess the traits as they applied to all vertebrate species.

\begin{tabular}{|c|c|c|c|c|}
\hline $\begin{array}{l}\text { Biological } \\
\text { trait } \\
\text { category }\end{array}$ & Trait & Definition & Pollutant & $\begin{array}{c}\text { Responses }(n) \\
L=\text { light; } N=\text { noise }\end{array}$ \\
\hline \multirow{7}{*}{$\begin{array}{l}\text { Ecological } \\
\text { sensitivity }\end{array}$} & activity pattern & Whether the vertebrate is primarily nocturnal or diurnal. & both & $L=123 ; N=96$ \\
\hline & latitude & $\begin{array}{l}\text { Where the vertebrate is primarily located latitudinally. If the } \\
\text { animal is migratory, this should be reflected in the trait "use } \\
\text { of migration" (see below). }\end{array}$ & both & $L=115 ; N=96$ \\
\hline & trophic level & $\begin{array}{l}\text { Whether the vertebrate is mainly a producer, primary } \\
\text { consumer, secondary consumer, or tertiary consumer. }\end{array}$ & both & $L=116 ; N=96$ \\
\hline & stratum in biosphere & $\begin{array}{l}\text { Whether the vertebrate is primarily fossorial, terrestrial, } \\
\text { arboreal, or aerial. }\end{array}$ & both & $\mathrm{L}=109 ; \mathrm{N}=96$ \\
\hline & vagility & $\begin{array}{l}\text { The degree the vertebrate can move throughout its } \\
\text { environment due to intrinsic factors. }\end{array}$ & both & $L=108 ; N=96$ \\
\hline & $\begin{array}{c}\text { habitat } \\
\text { specialization }\end{array}$ & $\begin{array}{l}\text { The degree the vertebrate specializes both spatially and } \\
\text { temporally. For example, requiring certain habitat } \\
\text { characteristics during the breeding season. }\end{array}$ & both & $L=111 ; N=96$ \\
\hline & $\begin{array}{c}\text { dietary } \\
\text { specialization }\end{array}$ & The degree the vertebrate's diet is specialized. & both & $\mathrm{L}=109 ; \mathrm{N}=96$ \\
\hline \multirow[t]{10}{*}{$\begin{array}{l}\text { Anatomical/ } \\
\text { physiological } \\
\text { sensitivity }\end{array}$} & $\begin{array}{l}\text { spectral color } \\
\text { resolution }\end{array}$ & $\begin{array}{l}\text { Ability to distinguish between many narrow wavelengths or } \\
\text { shades of color. For example, a species able to distinguish } \\
\text { teal and blue has greater color resolution compared to a } \\
\text { species that perceives teal and blue as the same color. }\end{array}$ & light & 99 \\
\hline & $\begin{array}{l}\text { ability to see wide } \\
\text { range of colors }\end{array}$ & $\begin{array}{l}\text { Ability to perceive different wavelengths. For example, a } \\
\text { species able to detect blue, green, and red wavelengths } \\
\text { has a greater ability than a species only able to detect blue } \\
\text { and green wavelengths. }\end{array}$ & light & 97 \\
\hline & $\begin{array}{l}\text { ability to see in low } \\
\text { light levels }\end{array}$ & Ability to see when there is very little light. & light & 101 \\
\hline & $\begin{array}{l}\text { dark adaptation } \\
\text { speed }\end{array}$ & $\begin{array}{l}\text { The speed at which the vertebrate's eyes adjust to new } \\
\text { illumination levels. }\end{array}$ & light & 100 \\
\hline & $\begin{array}{l}\text { visual-temporal } \\
\text { acuity }\end{array}$ & $\begin{array}{l}\text { Ability to distinguish visual events in time, for example the } \\
\text { ability to distinguish a steady light from a flickering light. }\end{array}$ & light & 98 \\
\hline & visual-spatial acuity & $\begin{array}{l}\text { Ability to resolve two points in space. For example, the } \\
\text { spatial acuity of humans is measured by optometrists using } \\
\text { eye charts with alphabet letters. }\end{array}$ & light & 96 \\
\hline & $\begin{array}{l}\text { auditory spectral } \\
\text { resolution }\end{array}$ & $\begin{array}{l}\text { Ability to distinguish between fine-scale differences in } \\
\text { sound. Analogous to "spectral color resolution. }\end{array}$ & noise & 93 \\
\hline & auditory bandwidth & $\begin{array}{l}\text { Ability to hear a wide range of auditory wavelengths. } \\
\text { Analogous to "ability to see wide range of colors. }\end{array}$ & noise & 94 \\
\hline & $\begin{array}{c}\text { ability to } \\
\text { discriminate in noisy } \\
\text { environments }\end{array}$ & $\begin{array}{l}\text { Ability to detect and distinguish informative signals from } \\
\text { other noises. }\end{array}$ & noise & 98 \\
\hline & $\begin{array}{l}\text { background noise } \\
\text { suppression }\end{array}$ & $\begin{array}{l}\text { Ability to ignore background noises (not habituation to } \\
\text { noises over time). }\end{array}$ & noise & 93 \\
\hline
\end{tabular}


bioRxiv preprint doi: https://doi.org/10.1101/2021.02.18.431905; this version posted February 19, 2021. The copyright holder for this preprint (which was not certified by peer review) is the author/funder, who has granted bioRxiv a license to display the preprint in perpetuity. It is made available under aCC-BY-NC-ND 4.0 International license.

\begin{tabular}{|c|c|c|c|c|}
\hline & $\begin{array}{l}\text { absolute hearing } \\
\text { thresholds }\end{array}$ & $\begin{array}{l}\text { The lowest sound level an organism can hear and that } \\
\text { elicits a response } 50 \% \text { of the time. }\end{array}$ & noise & 92 \\
\hline & $\begin{array}{l}\text { temporal resolving } \\
\text { power }\end{array}$ & $\begin{array}{l}\text { Ability to distinguish rapid changes in sounds over time. } \\
\text { Analogous to "visual-temporal acuity". }\end{array}$ & noise & 90 \\
\hline & $\begin{array}{l}\text { spatial resolving } \\
\text { power }\end{array}$ & $\begin{array}{l}\text { Ability to resolve the spatial location of a sound. Analogous } \\
\text { to "visual-spatial acuity". }\end{array}$ & noise & 93 \\
\hline $\begin{array}{l}\text { Adaptive } \\
\text { capacity }\end{array}$ & use of migration & $\begin{array}{l}\text { If the animal moves a long-distance from one area to } \\
\text { another. }\end{array}$ & both & $\mathrm{L}=109 ; \mathrm{N}=96$ \\
\hline
\end{tabular}

1

24 Sensitivity was defined to experts as the degree to which the survival, persistence, fitness, performance, or 3 regeneration of a species is reliant on current night light and noise levels or characteristics.

$4+$ Adaptive capacity was defined to experts based on the IPCC's 2001 Assessment Report (McCarthy et al., 2001):a 5 combination of strengths, attributes, and resources available to prepare for and undertake actions to reduce and/or 6 moderate adverse impacts and/or to exploit beneficial opportunities. This is the capacity of the species to persist in 7 situ, shift to suitable microhabitats, or migrate to suitable regions. 


\section{Results}

Nearly half of experts (48.4\%; $n=280$ responses) considered noise to be "very

3 important" or "important" in the system each expert studies or manages, while $14.6 \%$ of

4 experts considered noise "not important". Slightly fewer experts (43.5\%) considered

5 lighting to be "very important" or "important", and slightly more $(20.0 \%)$ considered

6 lighting to be "not important".

\section{$7 \quad$ Vulnerability to lighting and noise based on ecological traits}

Experts believed that elevated levels of lighting would increase the vulnerability

9 of species that are highly migratory, are more nocturnally active, and are considered

10 specialists when it comes to habitat use (Figure 1). Beyond these, several traits had

11 similar, and lower, weighted mean survey responses. Although of moderate importance

12 relative to other traits, there was consensus among the experts that dietary specialists

13 have more vulnerability than dietary generalists to lighting and noise (Figure 1).

14 Habitat use specialists were considered most vulnerable to increased levels of

15 noise (Figure 2). Activity pattern, vagility, stratum in the biosphere, and dietary breadth

16 had similar weighted mean responses, but beyond dietary specialization, there was little

17 consensus on the specific directionality or category of these traits (Figure 2).

\section{Vulnerability to lighting and noise based on anatomical and physiological traits}

Respondents largely agreed (74.3\%) that species with greater abilities to see in

20 low light, and those with the fastest dark adaption speed (50\% of responses) would be

21 relatively more susceptible to light pollution (Figure 3). There was little difference

22 among traits with lower weighted mean values but having the ability to see a wide range 
1 of colors ( $40.3 \%$ of responses) was considered to increase vulnerability the least

2 (Figure 3).

3 When considering elevated levels of noise pollution, auditory spectral resolution

4 and the ability to discriminate wavelengths of sound in noisy environments were

5 considered most likely to increase the vulnerability of species (Figure 4). For both,

6 experts generally agreed that having the most/highest ability of either trait increased

7 vulnerability the most (68.8\% and $73.4 \%$, respectively; Figure 4). Temporal resolving

8 power had the lowest mean survey response of all traits considered to influence the

9 vulnerability to noise pollution (Figure 4).

10 


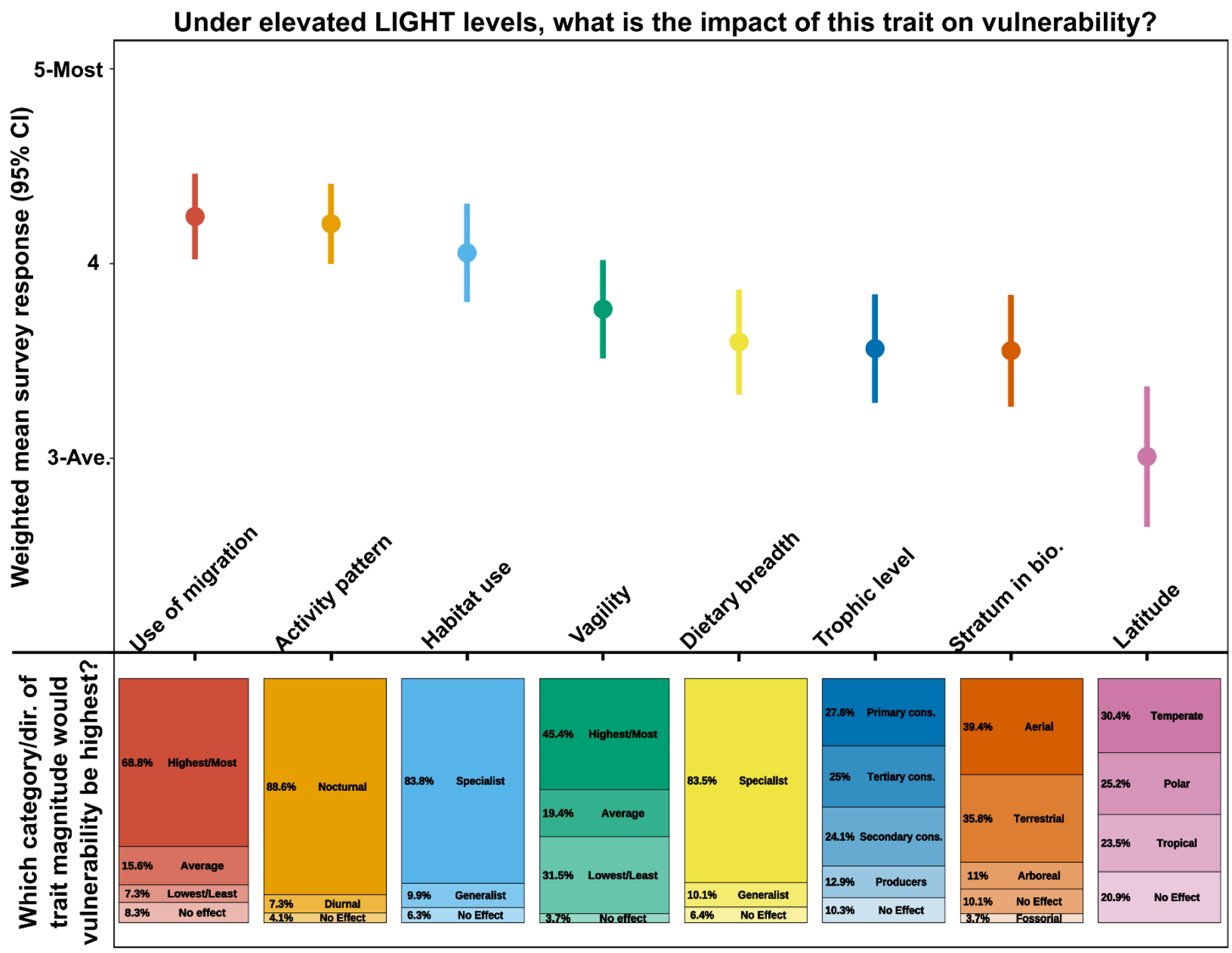

1 Figure 1.) Results indicating the responses of experts assessing how ecological sensitivity and adaptive

2 capacity traits influenced species' vulnerability to anthropogenic night light, and whether having more/less

3 of the trait, or specific attributes increased the magnitude of vulnerability. The $95 \%$ confidence intervals

4 associated with the weighted mean vulnerability for each trait were derived using weighted errors from

5 each respondent's confidence in their answer. Confidence was scored [0 - 5 scale] as the following: $5=$ "I

6 have extensive knowledge of this trait and am very confident in my response", 3 = "I have some

7 knowledge of this trait and am moderately confident in my response", 1 = "I have limited knowledge of

8 this trait and am not confident in my response", and $0=$ "none". 


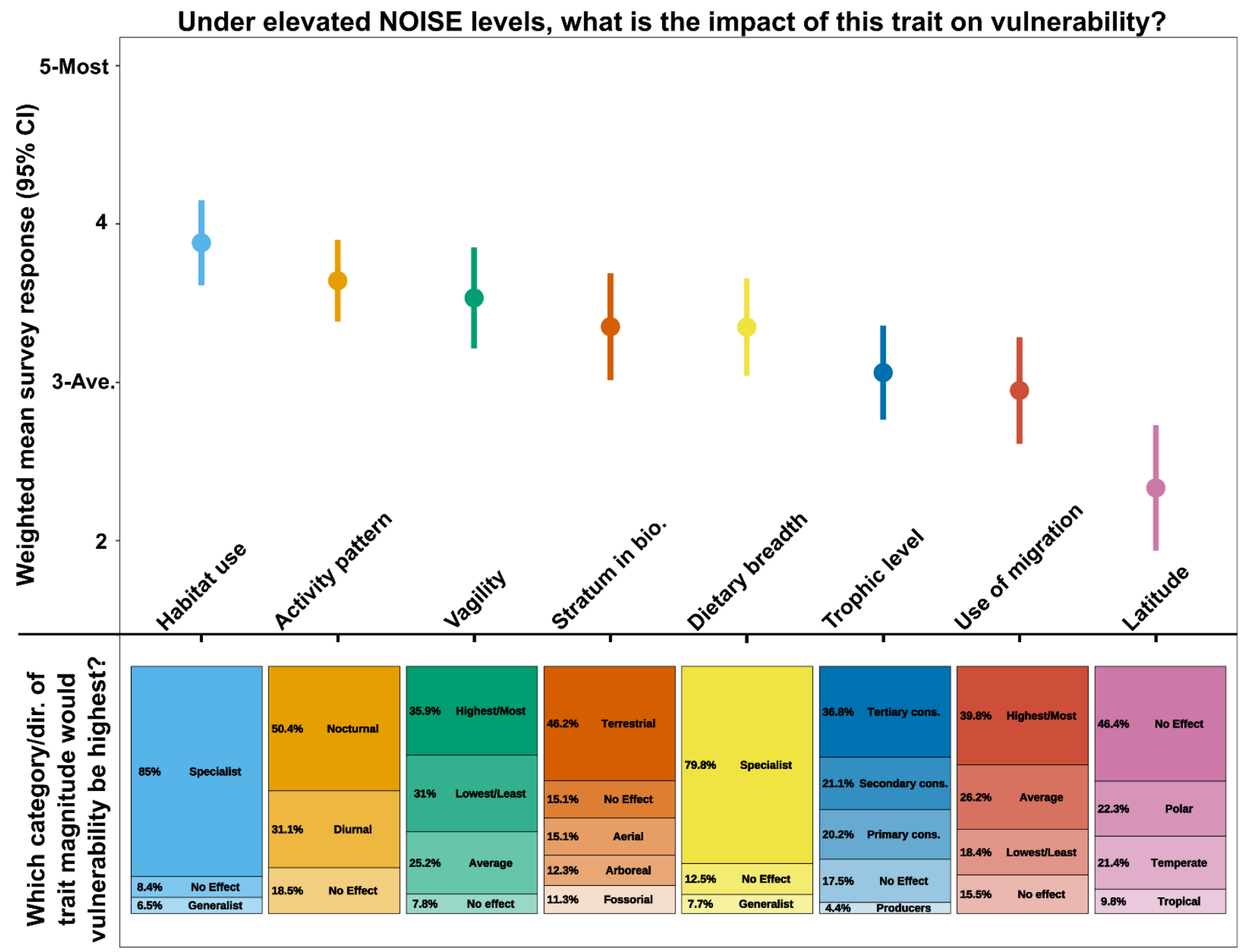

1 Figure 2.) Results indicating the responses of experts assessing how ecological sensitivity and adaptive

2 capacity traits influenced species' vulnerability to anthropogenic noise, and whether having more/less of

3 the trait, or specific attributes increased the magnitude of vulnerability. The $95 \%$ confidence intervals

4 associated with the weighted mean vulnerability for each trait were derived using weighted errors from

5 each respondent's confidence in their answer. Confidence was scored [0 -5 scale] as the following: $5=$ "I

6 have extensive knowledge of this trait and am very confident in my response", 3 = "I have some

7 knowledge of this trait and am moderately confident in my response", 1 = "I have limited knowledge of

8 this trait and am not confident in my response", and $0=$ "none". 


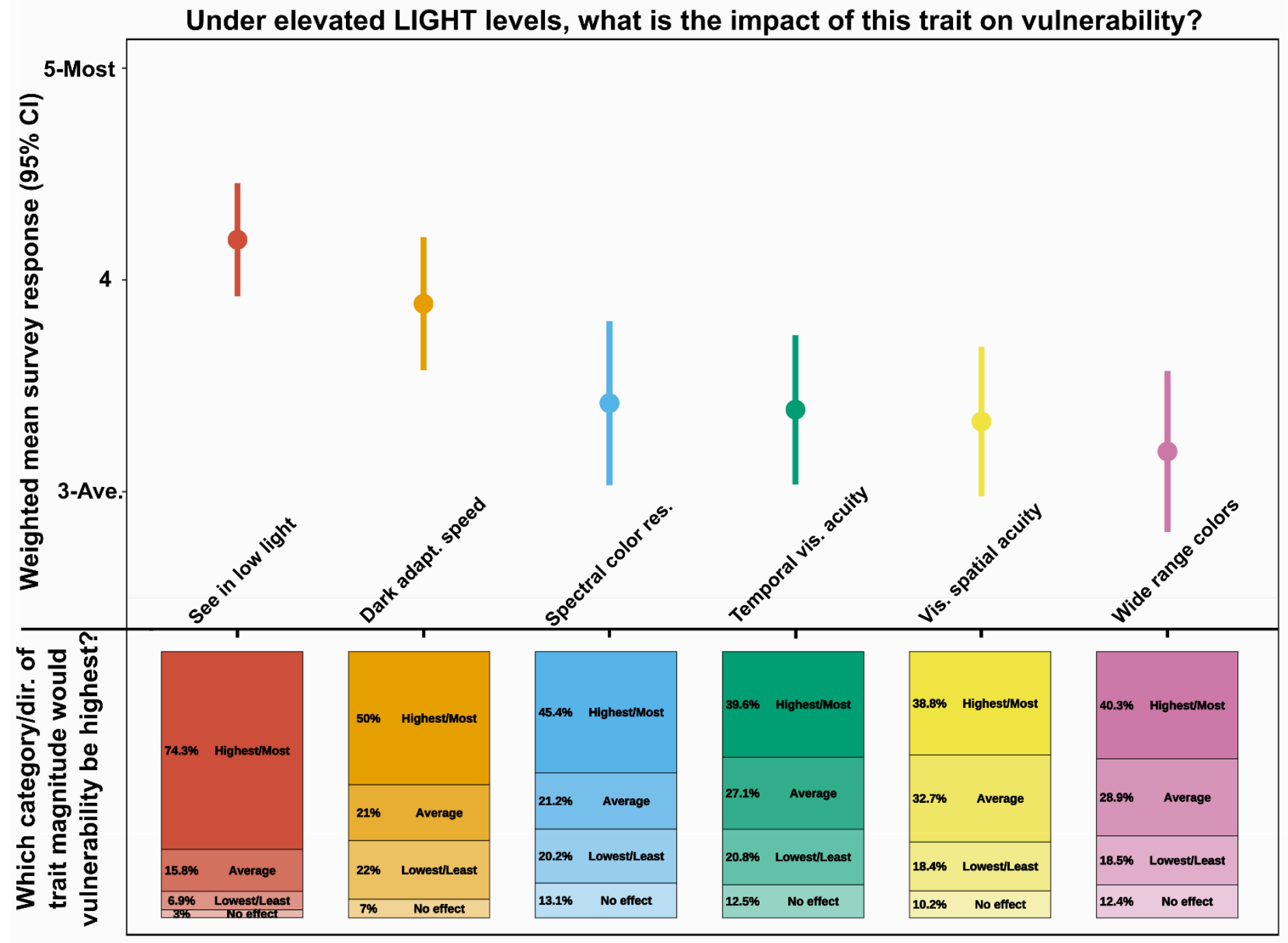

1 Figure 3.) Results indicating the responses of experts assessing how anatomical and physiological

2 sensitivity traits influenced species' vulnerability to anthropogenic night light, and whether having

3 more/less of the trait, or specific attributes increased the magnitude of vulnerability. The $95 \%$ confidence

4 intervals associated with the weighted mean vulnerability for each trait were derived using weighted

5 errors from each respondent's confidence in their answer. Confidence was scored [ $0-5$ scale] as the

6 following: 5 = "I have extensive knowledge of this trait and am very confident in my response", 3 = "I have

7 some knowledge of this trait and am moderately confident in my response", 1 = "I have limited knowledge

8 of this trait and am not confident in my response", and $0=$ "none". 


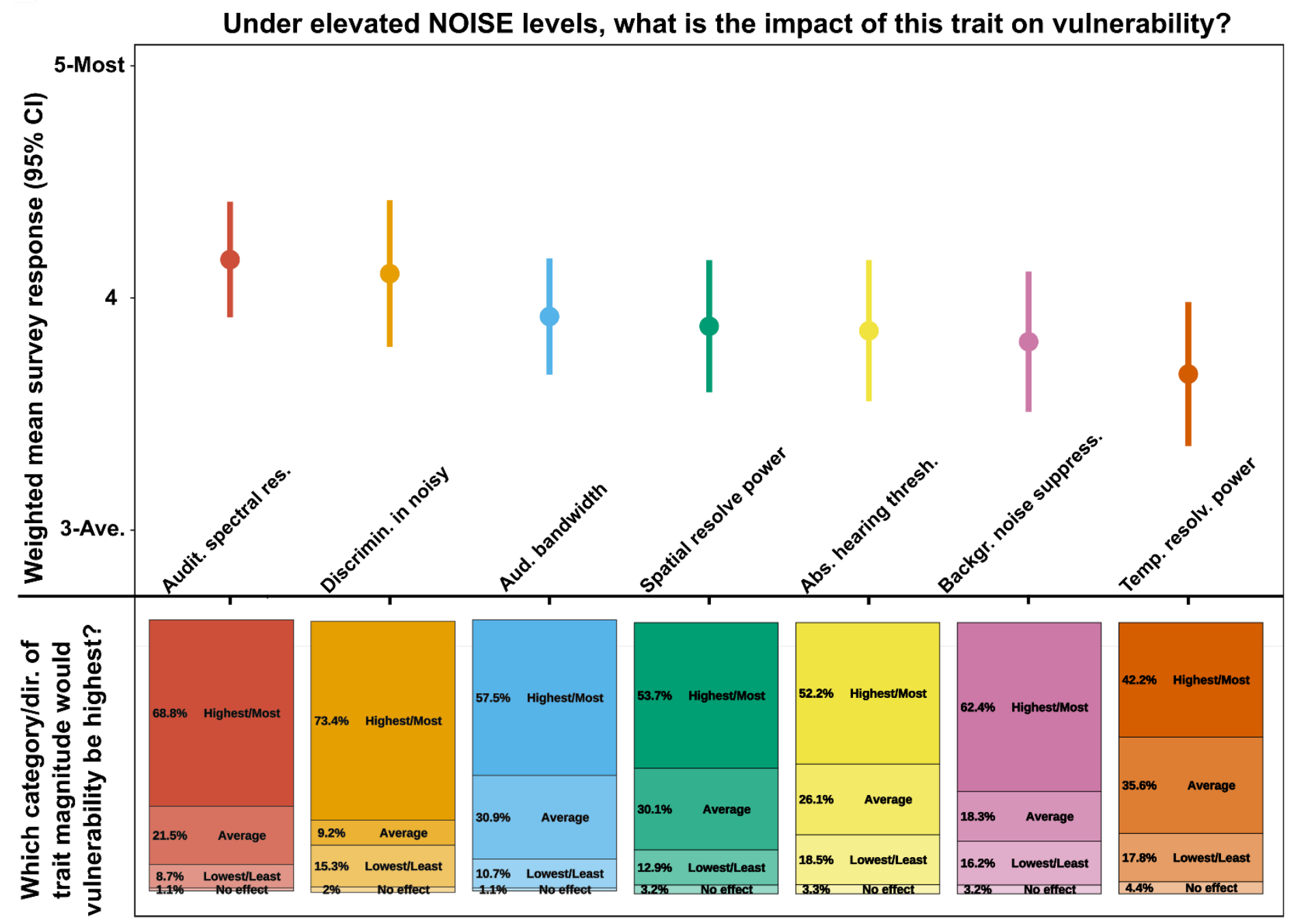

2 Figure 4.) Results indicating the responses of experts assessing how anatomical and physiological

3 sensitivity traits influenced species' vulnerability to anthropogenic noise, and whether having more/less of

4 the trait, or specific attributes increased the magnitude of vulnerability. The $95 \%$ confidence intervals

5 associated with the weighted mean vulnerability for each trait were derived using weighted errors from

6 each respondent's confidence in their answer. Confidence was scored [0 - 5 scale] as the following: $5=$ "I

7 have extensive knowledge of this trait and am very confident in my response", 3 = "I have some

8 knowledge of this trait and am moderately confident in my response", 1 = "I have limited knowledge of

9 this trait and am not confident in my response", and $0=$ "none". 


\section{Discussion}

We demonstrated that experts view sensory pollutants as important ecological

3 stressors in the system they research or manage. Furthermore, the experts considered several specific traits, especially those related to having a narrow niche breadth, that make species more vulnerable to sensory pollution. These traits can serve as heuristics when considering disturbances from lighting and noise in developing policies for species

7 that share the same traits.

In many ways, expert responses considering the threats from sensory pollutants

9 aligned with assessments of climate change vulnerability (Julliard, Jiguet, \& Couvet

10 2004; Clavel, Julliard, \& Devictor 2011) by emphasizing the sensitivity of species with

11 highly specialized habitat requirements. This analysis, however, expands upon this

12 finding by focusing on the intersection of niche specialization with highly developed

13 sensory function. The logic is simple: sensory degradation may critically depress

14 productivity among habitat specialists. Although noise and lighting have not been

15 featured in recovery plans for several habitat specialists, such as the spotted owl (Strix

16 occidentalis; USFWS 2011), black-footed ferret (Mustela nigripes; see below \& USFWS

17 2013), our analysis considering the input of hundreds of experts suggests they should be.

Here, we apply the framework of assessing sensory pollutant vulnerability to two

20 endangered species to illustrate why noise and lighting management seems apt for their

21 conservation plans. Gray bats (Myotis grisescens) have a nocturnal activity pattern, are

22 habitat specialists (95\% of the population roosts in 11 caves), and have eyes adapted to

23 very low light levels. These traits, combined with the responsiveness of their prey to 
1 lighting, suggest they will be especially vulnerable to light pollution (Figure 5). Indeed,

2 this species avoids areas affected by lighting (Cravens et al. 2018). Reduced light

3 pollution can be realized by decreasing lumen output (or eliminating lights), better

4 control over the spatial extent of lighting, limiting lighting to portions of the spectrum to

5 which the bats and their prey are less sensitive, and limiting the seasonal and diel

6 scheduling of lighting. For example, mitigating light pollution radiating from billboards or

7 facades, and setting curfew hours for when they are turned on (Schroer et al. 2020),

8 especially near the areas in which these animals roost, may be particularly effective.

The black-footed ferret has extremely specific habitat needs (USFWS 2013), and

10 ferrets have exceptionally capable hearing on par with humans below $20 \mathrm{kHz}$, and

11 extending to an upper frequency limit of $40 \mathrm{kHz}$ (Nodal and King 2014). Acute hearing is

12 crucial for hunting in subterranean burrows and for avoiding predation by

13 mesocarnivores above ground. Ferret ultrasonic hearing sensitivity enables them to

14 eavesdrop on many rodent vocalizations that humans cannot hear. The prairie dog

15 towns they require occur in open habitats lacking terrain shielding or sound attenuation

16 due to vegetation, so noise propagates without obstruction. Noise can be reduced at the

17 source through barriers, muffling, and scheduling of activities (Francis et al. 2011). For

18 both of these endangered species, adaptive management could reduce these pollutants

19 in a controlled experimental framework to quantify the benefits to these species and

20 allow for mitigation methods to iteratively improve over time, while facilitating their

21 adoption across many sites experiencing sensory pollution.

22 The aggregate responses of experts suggest that traits indicating highly

23 developed sensory function - sensitivity to lower stimulus levels, better spectral 
1 resolution, better capacity to hear in noise or rapidly dark adapt after exposure to light

2 - were generally regarded as indications that degraded sensory conditions would be

3 more problematic. For the latter two traits, varied responses likely arose because some

4 experts interpreted these traits as evolutionary evidence for heightened dependence on

5 these senses, while others regarded these traits as evidence of better capacity to

6 tolerate noise and lighting. Another grouping of responses exhibits similar divergence of

7 responses. Stratum in the biosphere, vagility, and migration can be assessed from two

8 perspectives. More vagile species may have more options to get away from adverse

9 sensory conditions, mitigating the effects of these pollutants. Alternatively, more vagile

10 species may be more heavily dependent upon sensory function for orientation,

11 navigation, and surveillance in habitats where they have no recent experience. In the

12 latter view, more philopatric species can use cognitive maps and recent familiarity with

13 habitat conditions to offset some loss of sensory function. A dramatic demonstration of

14 this latter perspective is the fatal, disorienting effects of light for highly migratory species

15 (Van Doren et al. 2017; McLaren et al. 2018).

Diel activity patterns emerged as the second most emphasized ecological factor

17 affecting sensitivity to noise and light (Figs. 1, 2). General consensus among experts

18 points to sensitivity among nocturnal species that alter behavior in response to variation

19 in artificial and natural light levels (Ditmer et al. 2020a, Willems et al. 2020, Prugh and

20 Golden 2014), plus nocturnal acoustic specialists that respond negatively to noise

21 exposure (Senzaki et al. 2016). Although the expert concordance was relatively high, it

22 is possible that this general consensus may reflect sparse evidence among diurnal

23 species, rather than an absence of effects. Studies of sensory function during sleep in 
1 wildife are sparse; however, new studies are suggestive of impacts from both noise and

2 light given the important role of hearing as a crucial alerting function during sleep and

3 because light exposure appears to influence multiple physiological systems. Light

4 disrupts the intensity, continuity and length of sleep in birds (Aulsebrook et al. 2020a,b)

5 and noise appears to fragment and degrade sleep in birds much as it does in humans

6 (Connelly et al. 2020). Thus, additional work is necessary to understand whether the

7 costs of noise and light exposure are greater for nocturnal or diurnal species.

8 Notably, some of the expert responses differed from our expectations based on

9 empirical studies. For example, we expected latitude to be considered an important trait

10 for vulnerability to lighting (Fig. 3). In contrast, tropical populations have very consistent

11 light cycles throughout the year, but changes in light radiance levels at twilight or loss of

12 night could lead to misalignments in diel activity patterns within communities. In

13 contrast, resident populations at high latitudes confront very long periods of night. When

14 exposed to artificial light, the duration may be substantial. Tropical and temperate

15 populations may also differ strongly in their responses to lighting depending on the

16 degree to which variation in light regimes is a phenological cue. Many, but not all,

17 temperate bird species appear to strongly advance their breeding season in response to

18 lighting (Kempenaerns et al. 2010; Senzaki et al. 2020). For hearing, low absolute

19 hearing thresholds would seem to be a prerequisite for elevated noise sensitivity. Some

20 hearing experts might reasonably counter that critical ratios are the more important

21 feature, but we were surprised by the lesser emphasis placed on this measure of

22 auditory performance in our survey. 
Although biological traits may change relatively slowly, lighting and noise are far

\section{2} less static, and may change dramatically within a population's or a species' range over the course of a single generation. Exposure is one of the three key components to vulnerability (Dawson et al. 2011). Geospatial models of skyglow have been developed (Falchi et al. 2016; Duriscoe et al. 2018), and Longcore et al. (2018) created an approach to predict species' responses to spectral outputs based on behavioral and visual characteristics. Spatially explicit estimates of anthropogenic noise for the United States were developed by Mennitt \& Fristrup (2016) and have been successfully applied to explaining how noise influences variation in avian reproductive success across North America (Senzaki et al. 2020). However, these geospatial models confront emerging challenges. The day-night band product from NASA's VIIRS system cannot detect photons with wavelengths shorter than $500 \mathrm{~nm}$. LED lamps that are rapidly proliferating through lighting upgrades have a prominent spectral peak at $470 \mathrm{~nm}$, so global predictions of sky glow will require recalibration, and minimum estimates (Kyba et al. 2015a). The geospatial sound map was a composite created from ten years of measurements. More extensive monitoring and more sophisticated analyses will be required to produce the capacity to measure or predict trends.

The limitations of the study point to crucial future research directions. First, we only considered negative impacts from lighting and noise. However, future work should consider all effects, such as increased foraging opportunities for crepuscular species exposed to lighting (Santos et al. 2010) and enhanced ability to track resource peaks which are increasingly shifted temporally due to climate change (Senzaki et al. 2020). We also did not assess the impacts on invertebrates, an important group of animals that 
1 contributes a large percentage to many vertebrate diets, that are highly sensitive to

2 changes in environmental cues (Klink et al. 2020; Owens et al. 2020), although $8 \%$ of

3 respondents identified as experts of invertebrate species. In addition, our rankings only

4 provide relative estimates of vulnerability. Combining these rankings with empirical

5 measures of species response to sensory pollutants, such as reductions in survival,

6 would mark an important advancement.

7 Despite the heightened understanding of the impacts that lighting and noise can

8 pose to species, as demonstrated in our survey responses, and the increasing

9 awareness that integrating sensory ecology is critical to conservation science (Dominoni

10 et al. 2020), few conservation plans account for the expanding sensory footprint of the

11 Anthropocene. Our study offers a generalized foundation for evaluating the ecological

12 consequences of noise and lighting, and provides justification for management actions

13 today. Although we understand enough to act now, and some governmental agencies

14 are beginning to recognize the threats to wildlife from sensory pollutants and provide

15 practical management solutions (see Mayer-Pinto, Dafforn, and Fobert 2020 for

16 Australia), further studies are needed to determine the most economical and effective

17 options to reduce sensory pollution at large enough scales to reduce harm to wildlife

18 populations and ecosystem functions. 
bioRxiv preprint doi: https://doi.org/10.1101/2021.02.18.431905; this version posted February 19, 2021. The copyright holder for this preprint (which was not certified by peer review) is the author/funder, who has granted bioRxiv a license to display the preprint in perpetuity. It is made available under aCC-BY-NC-ND 4.0 International license.

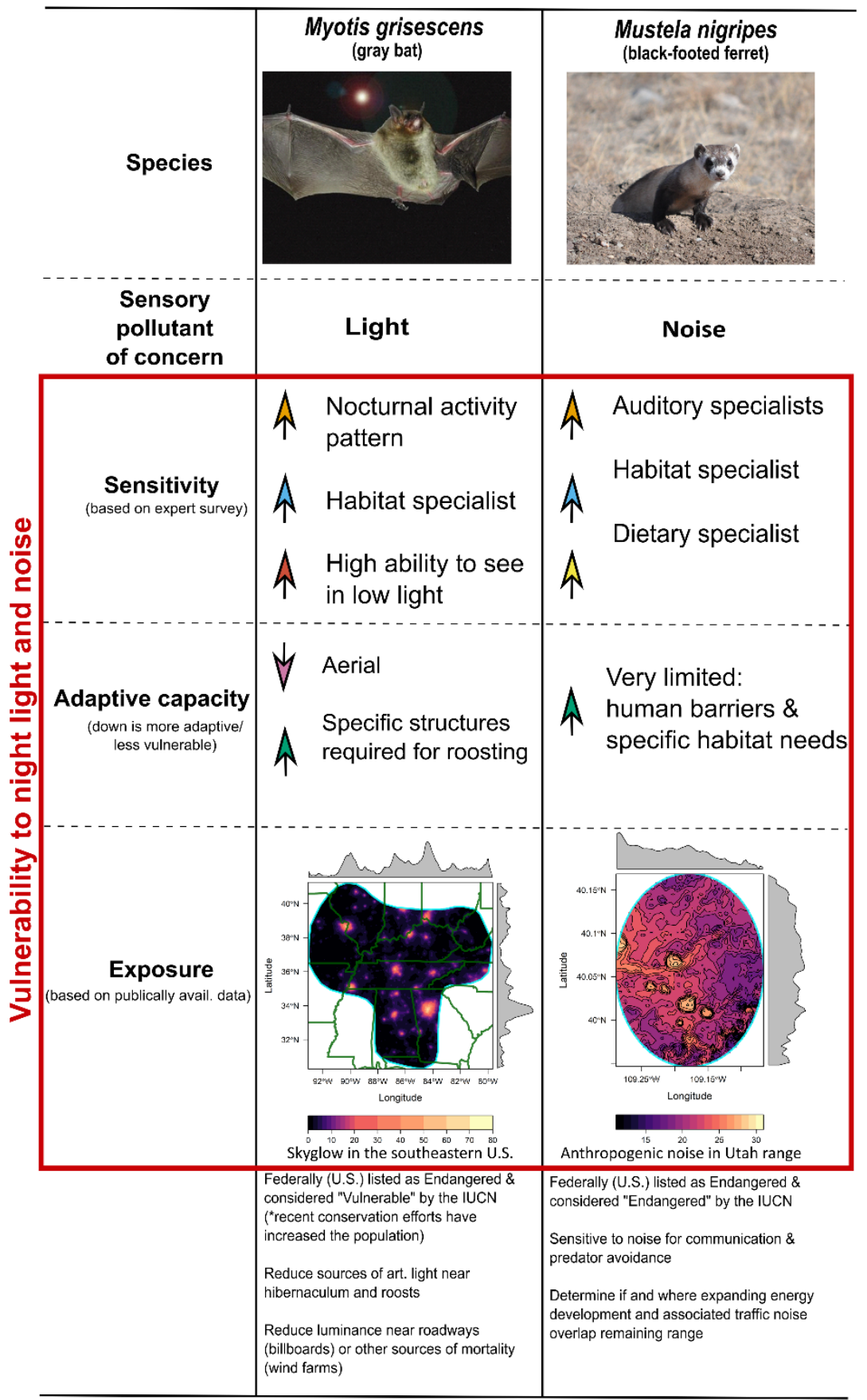

Figure 5.) Applying expert survey to developing vulnerability risk assessments and potential future research and/or management actions. Here we selected two species of conservation concern to demonstrate how the results of our survey can be used to assess the overall vulnerability of a species to sensory pollutants. We used the entire species' range of the gray bat in the southeastern U.S. and mapped the exposure based on estimates of nighttime skyglow developed by Duriscoe et al. 2018. For the black-footed ferret, we highlighted the species range in Utah only and mapped the estimated nighttime (ferrets are nocturnal) anthropogenic noise (L50) as developed by Mennitt \& Fristrup (2016).

8 Histograms show the mean values of each sensory pollutant across longitude and latitude. 


\section{Acknowledgements}

2 The work was supported by the NASA Ecological Forecasting Grant NNX17AG36G. K.

3 Markham assisted in developing and soliciting the survey.

\section{References}

Aulsebrook, A. E., Connelly, F., Johnsson, F. D., Jones, T. M., Mulder, R. A., Hall, M. L., Vyssotski, A. L., Lesku, J. A. (2020) White and amber light at night disrupt sleep physiology in birds. Curr. Biol., 30:18, R1009-R1062, 3495-3702.

Aulsebrook, A. E., Lesku, J. A., Mulder, R. A., Goymann, W., Vyssotski, A. L., \& Jones, T. M. (2020) Streetlights disrupt night-time sleep in urban black swans. Front. Ecol. Evol., 8, 131.

Barber, J. R., Crooks, K. R. \& Fristrup, K. M. (2010). The costs of chronic noise exposure for terrestrial organisms. Trends Ecol. Evol., 25, 180-189.

Bennie, J., Davies, T. W., Cruse, D., Inger, R., \& Gaston, K. J. (2015). Cascading effects of artificial light at night: resource-mediated control of herbivores in a grassland ecosystem. Philos Trans R Soc Lond B Biol Sci 370.

Bunkley, J. P., \& Barber, J. R. (2015). Noise reduces foraging efficiency in pallid bats (Antrozous pallidus). Ethology, 121(11), 1116-1121.

Buxton, R. T., McKenna, M. F., Mennitt, D., Fristrup, K., Crooks, K., Angeloni, L. \& Wittemyer, G. (2017). Noise pollution is pervasive in U.S. protected areas. Science, 356, 531-533. 
1 Cabrera-Cruz, S. A., Smolinsky, J. A., \& Buler, J. J. (2018). Light pollution is greatest within migration passage areas for nocturnally-migrating birds around the world. Sci Rep 8, 1-8.

Carwardine, J., O'Connor, T., Legge, S., Mackey, B., Possingham, H. P. \& Martin, T. G. (2012). Prioritizing threat management for biodiversity conservation. Conserv. Lett., 5, 196-204.

Chown, S. L. (2012). Trait-based approaches to conservation physiology: forecasting environmental change risks from the bottom up. Philos. Trans. R. Soc. B, 367, $1615-1627$.

Clavel, J., Julliard, R. \& Devictor, V. (2011). Worldwide decline of specialist species: toward a global functional homogenization? Front. Ecol. Environ., 9, 222-228.

Connelly, F., Johnsson, R. D., Aulsebrook, A. E., Mulder, R. A., Hall, M. L., Vyssotski, A. L., \& Lesku, J. A. (2020). Urban noise restricts, fragments, and lightens sleep in Australian magpies. Environ. Pollut., 267, 115484.

Cravens Z. M., Brown V. A., Divoll T. J., Boyles J. G., \& Matthew, S.. (2018). Illuminating prey selection in an insectivorous bat community exposed to artificial light at night. J. Appl. Ecol. 55, 705-713.

Dawson, T. P., Jackson, S. T., House, J. I., Prentice, I. C. \& Mace, G. M. (2011). Beyond predictions: biodiversity conservation in a changing climate. Science, $332,53-58$.

Ditmer, M. A., lannarilli, F., Tri, A. N., Garshelis, D. L., \& Carter, N. H. (2020b). Artificial night light helps account for observer bias in citizen science monitoring of an 
expanding large mammal population. J. Anim. Ecol. https://doi.org/10.1111/13652656.13338

Ditmer, M. A., Stoner, D. C., Francis, C. D., Barber, J. R., Forester, J. D., Choate, D. M., ... Carter, N. H. (2020a). Artificial nightlight alters the predator-prey dynamics of an apex carnivore. Ecography. https://doi.org/10.1111/ecog.05251

Dominoni, D. M., Halfwerk, W., Baird, E., Buxton, R. T., Fernández-Juricic, E., Fristrup, K. M., ... Barber, J. R. (2020). Why conservation biology can benefit from

Duriscoe, D. M., Anderson, S. J., Luginbuhl, C. B. \& Baugh, K. E. (2018). A simplified model of all-sky artificial sky glow derived from VIIRS Day/Night band data. J

Falchi, F., Cinzano, P., Duriscoe, D., Kyba, C. C. M., Elvidge, C. D., Baugh, K., Portnov, sensory ecology. Nat. Ecol. Evol., 1-10.

Foden, W. B., Butchart, S. H. M., Stuart, S. N., Vié, J.-C., Akçakaya, H. R., Angulo, A., ... Mace, G. M. (2013). Identifying the world's most climate change vulnerable species: A systematic trait-based assessment of all birds, amphibians and corals.

19 Francis, C. D. (2015). Vocal traits and diet explain avian sensitivities to anthropogenic noise. Glob. Chang. Biol., 21, 1809-1820.

21 Francis, C. D. \& Barber, J. R. (2013). A framework for understanding noise impacts on wildlife: an urgent conservation priority. Front. Ecol. Environ., 11, 305-313. 
1 Francis, C. D., Paritsis, J., Ortega, C. P. \& Cruz, A. (2011). Landscape patterns of avian habitat use and nest success are affected by chronic gas well compressor noise. Landsc. Ecol., 26, 1269-1280.

4 Garrett, J. K., Donald, P. F. \& Gaston, K. J. (2019). Skyglow extends into the world's Key Biodiversity Areas. Anim. Conserv., n/a.

6 Gaston, K. J., Bennie, J., Davies, T. W. \& Hopkins, J. (2013). The ecological impacts of nighttime light pollution: a mechanistic appraisal. Biol. Rev., 88, 912-927.

8 Gaston, K. J., Davies, T. W., Nedelec, S. L. \& Holt, L. A. (2017). Impacts of artificial light at night on biological timings. Annu. Rev. Ecol. Evol. Syst., 48, 49-68.

10 Gerber, B. D., Converse, S. J., Muths, E., Crockett, H. J., Mosher, B. A. \& Bailey, L. L. (2018). Identifying species conservation strategies to reduce disease-associated declines. Conserv. Lett., 11, e12393.

13 Helske, J. (2018). diagis: Diagnostic plot and multivariate summary statistics of weighted samples from importance sampling. light at night as a driver of evolution across urban-rural landscapes. Front. Ecol. Environ., 16, 472-479. makes a species at risk? Glob. Chang. Biol., 10, 148-154. 
1 Kempenaers, B., Borgström, P., Loës, P., Schlicht, E., \& Valcu, M. (2010). Artificial night lighting affects dawn song, extra-pair siring success, and lay date in songbirds. Curr. Biol., 20, 1735-1739.

Klein, C. J., Beher, J., Chaloupka, M., Hamann, M., Limpus, C. \& Possingham, H. P.

Kleist, N. J., Guralnick, R .P., Cruz, A. \& Francis, C. D. (2017). Sound settlement: noise (2017). Prioritization of marine turtle management projects: A protocol that

(1)
accounts for threats to different life history stages. Conserv. Lett., 10, 547-554.

Klink, R. van, Bowler, D. E., Gongalsky, K. B., Swengel, A. B., Gentile, A. \& Chase, J. M. (2020). Meta-analysis reveals declines in terrestrial but increases in

13 Kyba, C. C. M., Garz, S., Kuechly, H., Miguel, A. S. de, Zamorano, J., Fischer, J. \& freshwater insect abundances. Science, 368, 417-420.

19 Kyba, C. C. M., Tong, K. P., Bennie, J., Birriel, I., Birriel, J. J., Cool, A., ... Gaston, K. J.

Kyba, C. C. M., Kuester, T., Sánchez de Miguel, A., Baugh, K., Jechow, A., Hölker, F., ... Guanter, L. (2017). Artificially lit surface of Earth at night increasing in radiance and extent. Sci $A d v, 3$.

21 Longcore, T. \& Rich, C. (2004). Ecological light pollution. Front. Ecol. Environ., 2, 191198. 
1 Longcore, T., Rodríguez, A., Witherington, B., Penniman, J. F., Herf, L. \& Herf, M. (2018). Rapid assessment of lamp spectrum to quantify ecological effects of light at night. J. Exp. Zool. A Ecol. Integr. Physiol., 329, 511-521.

Mayer-Pinto, M., Dafforn, K. A., \& Fobert, E. (2020). Knowledge exchange to improve research and management of the impacts of artificial light at night. Austral Ecol.

Martin, T. G., Burgman, M. A., Fidler, F., Kuhnert, P. M., Low-Choy, S., Mcbride, M. \& Mengersen, K. (2012). Eliciting expert knowledge in conservation science. Conserv. Biol., 26, 29-38.

Mason, J. T., McClure, C. J., \& Barber, J. R. (2016). Anthropogenic noise impairs owl hunting behavior. Biol. Conserv., 199, 29-32.

McCarthy, J. J., Canziani, O. F., Leary, N. A., Dokken, D. J. \& White, K. S. (2001). Climate change 2001: Impacts, adaptation, and vulnerability: contribution of Working Group II to the Third Assessment Report of the Intergovernmental Panel on Climate Change. Cambridge University Press.

McLaren, J. D., Buler, J. J., Schreckengost, T., Smolinsky, J. A., Boone, M., Loon, E. E. van, Dawson, D. K., \& Walters, E. L. (2018). Artificial light at night confounds broad-scale habitat use by migrating birds. Ecology Letters 21, 356-364.

Mennitt, D. J. \& Fristrup, K. M. (2016). Influence factors and spatiotemporal patterns of environmental sound levels in the contiguous United States. Noise Control Eng. J., 64, 342-353.

Nodal, F. R., \& King, A. J. (2014). Hearing and Auditory Function in Ferrets. In Biology and Diseases of the Ferret. pp. 685-710. John Wiley \& Sons, Ltd. 
1 Ouyang, J. Q., Davies, S. \& Dominoni, D. (2018). Hormonally mediated effects of artificial light at night on behavior and fitness: linking endocrine mechanisms with function. J. Exp. Biol., 221, jeb156893.

Owens, A. C. S., Cochard, P., Durrant, J., Farnworth, B., Perkin, E. K., \& Seymoure, B. (2020). Light pollution is a driver of insect declines. Biol. Conserv. 241, 108259.

R Core Team. (2019). R: A language and environment for statistical computing. $\mathrm{R}$ Foundation for Statistical Computing, Vienna, Austria.

11 Read, J., Jones, G., \& Radford, A. N. (2014). Fitness costs as well as benefits are analysis reveals divergent responses of nocturnal mammals to lunar cycles. $\mathrm{J}$. Anim. Ecol. 83, 504-514.

Prugh, L. R., \& Golden, C. D. (2014). Does moonlight increase predation risk? Meta-

(1)

8

(1)
important when considering responses to anthropogenic noise. Behav Ecol25, $4-7$.

Rolland, R. M., Parks, S. E., Hunt, K. E., Castellote, M., Corkeron, P. J., Nowacek, D.

(5)

$$
\text { P., Wasser, S. K., \& Kraus, S. D. (2012). Evidence that ship noise increases }
$$
stress in right whales. $P R$ SOC B 279, 2363-2368.

Santos, C. D., Miranda, A. C., Granadeiro, J. P., Lourenço, P. M., Saraiva, S. \& Palmeirim, J. M. (2010). Effects of artificial illumination on the nocturnal foraging of waders. Acta Oecol., 36, 166-172.

20 Schroer, S., Huggins, B. J., Azam, C. \& Hölker, F. (2020). Working with inadequate 21 tools: Legislative shortcomings in protection against ecological effects of artificial 22 light at night. Sustainability, 12, 2551. 
1 Senzaki, M., Barber, J., Phillips, J., Carter, N., Cooper, C., Ditmer, M., .. Francis, C. (2020). Sensory pollutants alter bird phenology and fitness across a continent. Nature. https://doi.org/10.1038/s41586-020-2903-7

Senzaki, M., Yamaura, Y., Francis, C. D., \& Nakamura, F. (2016). Traffic noise reduces foraging efficiency in wild owls. Scientific reports, 6, 30602.

Shannon, G., McKenna, M. F., Angeloni, L. M., Crooks, K. R., Fristrup, K. M., Brown, E., ... Wittemyer, G. (2016). A synthesis of two decades of research documenting

Slabbekoorn, H., \& Bouton, N. (2008). Soundscape orientation: a new field in need of the effects of noise on wildlife. Biol. Rev., 91, 982-1005. sound investigation. Animal Behaviour 76, e5-e8.

Swaddle, J. P., Francis, C. D., Barber, J. R., Cooper, C. B., Kyba, C. C. M., Dominoni,

14 Touzot, M., Teulier, L., Lengagne, T., Secondi, J., Théry, M., Libourel, P.-A., Guillard, L., \& Mondy, N. (2019). Artificial light at night disturbs the activity and energy

(6)
allocation of the common toad during the breeding period. Conserv Physiol 7.

U.S. Fish and Wildlife Service [USFWS]. 2011. Revised recovery plan for the northern spotted owl (Strix occidentalis caurina). U.S. Department of Interior, Portland,

U.S. Fish and Wildlife Service [USFWS]. 2013. Black-footed ferret draft recovery plan. 
1 Van Doren, B. M. V., Horton, K. G., Dokter, A. M., Klinck, H., Elbin, S. B. \& Farnsworth,

2 A. (2017). High-intensity urban light installation dramatically alters nocturnal bird migration. PNAS, 114, 11175-11180.

4 Willems, J. S., J. N. Phillips, R. A. Vosbigian, F. X. Villablanca \& Francis, C. D. (In press). Night lighting and anthropogenic noise alter the activity and body condition of pinyon mice (Peromyscus truel). Ecosphere 